\title{
Serious Hazards of Transfusion Haemovigilance - The UK Experience
}

\author{
Paula HB Bolton-Maggs ${ }^{1}$ and Hannah Cohen ${ }^{2}$ on behalf of the Serious Hazards of Transfusion Steering Group \\ 1. Consultant Haematologist and Honorary Senior Lecturer, University of Manchester; 2. Consultant Haematologist and Honorary Senior Lecturer, \\ Department of Haematology, University College London Hospitals NHS Foundation Trust and University College London, UK
}

\begin{abstract}
Haemovigilance is an important method for the surveillance of adverse events. The UK Serious Hazards of Transfusion (SHOT) scheme was set up in 1996 and collects adverse events resulting from the transfusion of blood and its components. The information collected is presented at an annual symposium and published in report form, and has resulted in several changes in blood transfusion practices - in the blood services at donor collection, within hospital laboratories and at the patient's bedside - resulting in improved safety and a reduction in serious events and deaths. SHOT reporting has stimulated many other initiatives, such as national transfusion audit and education strategies, endorsed by the government in order to reduce harm and increase transfusion safety.
\end{abstract}

\section{Keywords}

Serious Hazards of Transfusion (SHOT), haemovigilance, transfusion safety

Disclosure: The authors have no conflicts of interest to declare.

Received: 29 February 2012 Accepted: 28 March 2012 Citation: European Oncology \& Haematology, 2012;8(2):127-9 DOI: 10.17925/EOH.2012.08.02.127 Correspondence: Paula HB Bolton-Maggs, SHOT Office, Manchester Blood Centre, Plymouth Grove, Manchester M13 9LL, UK. E: paula.bolton-maggs@nhsbt.nhs.uk

'Haemovigilance' is defined by the International Haemovigilance Network (IHN) as 'a set of surveillance procedures covering the whole transfusion chain, from the collection of blood and its components to the follow-up of recipients, intended to collect and assess information on unexpected or undesirable effects resulting from the therapeutic use of labile blood products and to prevent their occurrence or recurrence'.1 An international agreement on the definition of non-infectious adverse transfusion reactions was reached in 2006, and proposals have recently been published. ${ }^{2}$

About three million blood components are issued each year to hospitals from the UK transfusion services. Haematologists and other clinicians require reliable information about adverse events to provide an assessment of risk and to develop guidelines. The emergence of serious infectious complications (particularly HIV) in the 1980s and 1990s and anxiety about the possible transmission of variant creutzfeld-Jacob disease (VCJD) by blood transfusion, together with a suspicion that identification errors were occurring at hospital level (isolated case reports), prompted action. A working group was set up in the UK in 1994 to plan for a UK-wide haemovigilance system, additionally as part of the preparations for the new EU Blood Directive, which would set some standards in EU law (in 2005) for the provision of blood supplies. The working group modelled the new reporting system on other UK confidential enquiries and worked in close cooperation with the Health Protection Agency (HPA), which had started collaborating with the National Blood Services to collect information on viral infections and their transmission by transfusion.

The Serious Hazards of Transfusion (SHOT) scheme was introduced in the UK as a confidential haemovigilance scheme in 1996. Many different groups and organisations have some part in the transfusion process, and SHOT reporting has stimulated both new initiatives from and increased collaboration between these partner groups. SHOT is affiliated to the Royal College of Pathologists and is overseen by a steering group, which has wide representation from the UK Royal colleges and professional bodies as well as from speciality groups involved in blood transfusion. SHOT is independent and professionally led. SHOT analyses data collected over 12-month periods, presenting the results at a national symposium and publishing annual reports (available at www.shotuk.org). The scheme is funded by the four UK blood services (England, Scotland, Wales and Northern Ireland) and is now managed by a team based in Manchester. Initially, hospital haematologists and blood banks participating in the UK national quality assurance scheme for serology were invited to cooperate. When events were reported, a detailed questionnaire was sent out. Since January 2010, the reporters use a web-based system, which is easier for both users and analysts. Reports are reviewed by a clinical incidents specialist or a laboratory incidents specialist, who can then make further enquiries as indicated to ensure that the events are fully reported and appropriately classified.

The focus at SHOT has always been on patient safety, therefore report categories include events that put the patient most at risk, particularly ABO-incompatible transfusions. The reported events can be broadly divided into those that are physiological (or pathological) reactions to transfusion (such as acute transfusion reactions or transfusion-related acute lung injury [TRALI]) and those resulting from one or more errors in the transfusion process. Over the years, some categories have been modified; for example, it has been recognised that not all cases with pulmonary symptoms after transfusion have TRALI or transfusion-associated cardiac overload (TACO), but that there is another category for analysis from which we may learn more, i.e., 'transfusion-associated dyspnoea' (TAD). Information about cases of TACO has been collected since 2008. In the early years, we did not seek to report events occurring with the administration of anti-D 


\section{Figure 1: Current Reporting Categories of Adverse Events Monitored in the UK by the Serious Hazards of Transfusion (SHOT) Scheme and Cumulative Event Occurrence (in \%) Over 14 Years}

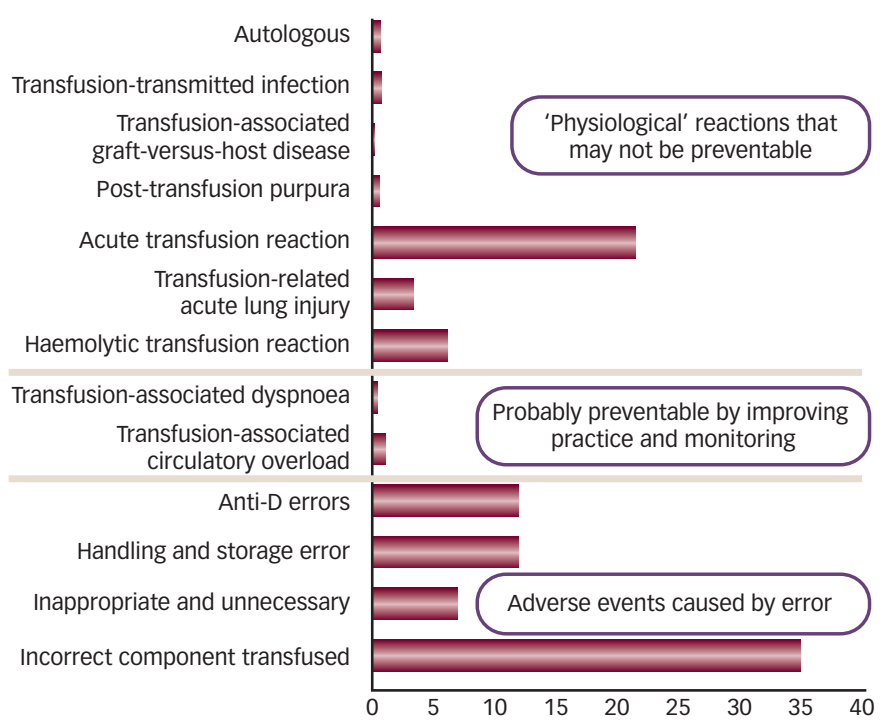

Cumulative data (more than 8,000 events) from 14 years (1996-2010) of haemovigilance reporting in the UK, with each category expressed as a percentage of the total events (excluding near-miss events). The precise definitions are published on the SHOT website (www.shotuk.org) and are consistent with the definitions found on the International Haemovigilance Network website (www.ihn-org.com)

immunoglobulin (given to rhesus D-negative women as prophylaxis against haemolytic disease of the newborn) but, as we received some reports, this category was formally introduced and has demonstrated a significant incidence of errors which needs addressing by better training and education of all the staff involved. Near-miss events are also reported, are informative and have been analysed in detail in the most recent reports. ${ }^{3}$ In recent years, SHOT has also reported events relating to information technology (IT) systems, often due to misuse of, or errors with, blood tracking systems, failure to merge or reconcile records, and missing or ignoring warning flags on patient records; these illustrate difficulties with reliance on IT. The current SHOT reporting categories are shown in Figure 1. Paediatric cases are analysed together in a separate chapter of each report to examine issues that particulary relate to children - for example, appropriate volume of transfusion and particular indications and adverse events in the neonatal period.

The most serious adverse outcome of transfusion is death. Adverse events can also result in major morbidity, which is defined by at least one of the following: intensive care admission and/or ventilation; dialysis and/or renal impairment; major haemorrhage from transfusion-induced coagulopathy; evidence of intravascular haemolysis; life-threatening acute reaction requiring immediate medical intervention; a reaction resulting in a low or high haemoglobin level of a degree sufficient to cause risk to life without immediate medical intervention; and persistent viral infection and acute symptomatic confirmed infection. In addition, anti-D or anti-K sensitisation in a woman of child-bearing potential is regarded as carrying potential risk of major morbidity.

Over the 14 years of reporting, the number of hospitals participating has increased from $22 \%$ in 1996 to $92 \%$ by 2000/01 and to $95 \%$ in 2010, as the benefits of the analyses have been evident. Initially voluntary, SHOT reporting is now universally supported and endorsed by accreditation agencies and the UK Departments of Health.

\section{Improved Safety of Transfusion}

The identification of adverse events and analysis of their causes inform other organisations involved in transfusions and have resulted in changes of practice. Changes at donor collections have resulted in safer products; for example, after the recognition that TRALI, which used to be the leading cause of major morbidity and mortality, was more often associated with female donors, the transfusion services initiated risk-reduction strategies in 2003/04. These strategies included the use of male donors to provide fresh frozen plasma (FFP) and plasma for suspension of platelet pools, the preferential recruitment of male apheresis platelet donors and the screening of female donors for human leukocyte antigen (HLA) or human neutrophil antigen (HNA) antibodies. These measures have been associated with a gratifying and consistent reduction in TRALIS.

The analysis of transfusion-transmitted infections (TTIS) demonstrated several bacterial infections (some fatal) from platelet transfusions, which have been reduced by changes in practice at donation, including diversion of the first $20 \mathrm{ml}$, improved skin cleaning techniques, visual inspection of units and screening of platelet donations for bacterial contamination. Other TTIs are very rare, with no viral infections since 2004

The introduction of leucodepletion in the UK in 1999 (primarily to reduce the risk of VCJD transmission) has been followed by a reduction of transfusion-related graft-versus-host disease (TA-GVHD), ${ }^{5}$ with no cases observed in the last 10 years despite numerous reports of failure to request irradiated products for some patients at risk (stem cell transplant recipients, children with immune deficiency, patients with Hodgkin's disease and patients who have received fludarabine).

The findings and subsequent recommendations from SHOT have also informed the continued development and revision of national transfusion guidelines produced by the British committee for Standards in Haematology (BCSH), which can be viewed on the BCSH website (www.bcshguidelines.com).

From the outset, SHOT has emphasised the need for a national body with relevant expertise and resources to advise the government on priorities for improvement in blood safety, ${ }^{6}$ and was pleased to see the establishment of the Advisory Committee on the Safety of Blood, Tissues and Organs (SaBTO) in 2007, which replaced the Advisory Committee on the Microbiological Safety of Blood, Tissues and Organs for Transplantation (MSBTO).

\section{Improving Safety by Improving Training and Competence Assessment}

Early reports identified a significant number of preventable errors ${ }^{7}$ and cumulative reporting shows that about $50 \%$ of events are avoidable (see Figure 1). Mistakes are mostly caused by failure in basic, simple steps, particularly the correct identification of the patient at the time of blood sampling for group and antibody screen; the avoidance of mistakes in the laboratory, such as transposition of samples or mislabelling; and later the correct identification of the recipient at the time of transfusion (i.e., right blood, right patient). This indicates the need for better training. SHOT collects incidents where patients have received the wrong component. This puts patients at risk of serious events, particularly that 
of receiving a wrong transfusion. The most serious of these risks is an $\mathrm{ABO}$ incompatibility, which may cause death or severe morbidity.

Death or serious harm as a result of the inadvertent transfusion of ABO-incompatible blood components was included in the Department of Health's 'never events' list in 2011/12. ${ }^{3}$ A guideline for safer handling and administration was developed by the $\mathrm{BCSH} .{ }^{8,9}$ Hospitals were encouraged to set up transfusion committees. ${ }^{10}$ The Department of Health, informed by the SHOT haemovigilance reporting, developed and supported projects for improved practice such as the 'better blood transfusion' health service circulars, ${ }^{10-12}$ which advise hospitals of their responsibilities. Hospitals were encouraged to employ 'transfusion practitioners' (TPS) who provide education, training and supervision, thereby promoting the appropriate use of blood and its components (the implementation of TPS was a SHOT recommendation in its 2000/2001 annual report ${ }^{13}$ ). Most UK hospitals now have between one and three TPS. SHOT findings underpinned the development of the Chief Medical Officer's National Blood Transfusion Committee (NBTC) in England and its counterparts in Scotland, Wales and Northern Ireland, which provide a powerful infrastructure to drive good and safe transfusion practice at hospital level.

The National Patient Safety Agency (NPSA, set up in 2000) has published 'safer practice notices', which require appropriate action including, in November 2006, Right Patient, Right Blood..$^{14}$ Developed collaboratively with SHOT and the NBTC, it instructs all organisations who are responsible for transfusions to implement an action plan for competency-based training and assessment for all staff members involved in transfusions. Changes in clinical practice, such as mandatory training and competency testing, have resulted in a significant reduction of wrong blood incidents.

The identification of laboratory issues and concerns about standards of transfusion practice following economies of staffing and merging of departments resulted in the formation of the SHOT-initiated, and Institute of Biomedical Science-led, UK Transfusion Laboratory Collaborative (UKTLC). The recommendations of the UKTLC provide minimum standards for hospital transfusion laboratories and address staffing, technology, training and competence. ${ }^{15}$ They are intended to encourage the effective and appropriate use of technology and staff in hospital transfusion laboratories within the framework of current legislative requirements, and to achieve the minimum standards of proficiency and practice set by the Health Professions Council and required by the UK 2005 Blood Safety and Quality Regulations (BSQR). ${ }^{16}$
SHOT reporting also informs the National Comparative Audit of Blood Transfusion programme (www.nhsbtaudits.co.uk). This aims to look at the quality of the administration of blood to patients and also at the practice of prescribing blood and blood components against national standards (e.g., as set out in the BCSH guidelines ${ }^{8,9}$ ), which have demonstrated variations in practice and further areas for improvement.

\section{Links to European Legislation}

In 2005, the EU blood safety and quality regulations became law in the UK, and the competent authority managing this is under the Medicines and Healthcare products Regulatory Agency (MHRA). ${ }^{16}$ The law requires reporting of any adverse events related to process failure in the quality management systems within blood establishments or in hospital blood banks, but adverse events relating to clinical incidents are only collected by SHOT. There is some overlap and we are currently working to harmonise the reporting systems for hospitals. Many countries now have haemovigilance schemes and are collaborating under the umbrella of the IHN (which has a wesbite that can be found at www.ihn-org.com). The IHN promotes the exchange of information and collaboration in order to standardise definitions and promote benchmarking, and organises an annual symposium. Originally set up within Europe, the IHN now has a wide range of national members from across the world.

\section{Emerging Issues}

In recent years, there has been an increase in reports of TACO. This is a particular risk in the elderly and where transfusions are not appropriately monitored. Similarly, instances of inappropriate and unnecessary transfusion may be caused by acting on wrong results (due to wrong sample; unrecognised clotted sample; transcription errors; use of inappropriate point-of-care machines, including blood gas analysers that have not been quality-assured for this purpose, or mistaken use of blood glucose machines to measure haemoglobin) or poor management of iron deficiency. There is concern about timely and adequate transfusion in cases of major haemorrhage, since patients may die. The NPSA has published a 'rapid response report', The transfusion of blood and blood components in an emergency, ${ }^{17}$ which mandates reporting of life-threatening delayed or under-transfusion to SHOT.

\section{Conclusion}

The overall outcome of all this cooperative activity - collection of data and publication of recommendations by SHOT, followed by actions recommended and mandated by the departments of health and other national bodies - has been a marked increase in the number of events reported but a reduction in deaths and serious morbidity for patients.
1. International Haemovigilance Network, Definition of Haemovigilance, 2012. Available at: www.hn-org.com/about/definition-of-haemovigilance/ (accessed 25 April 2012)

2. International Society of Blood Transfusion, Working Party on Haemovigilance, Proposed Standard Definitions for Surveillance of Non Infectious Adverse Transfusion Reactions, International Haemovigilance Network, July 2011. Available at: www.isbtweb.org/fileadmin/user_upload/WP_on_Haemovigilanc e/ISBT definitions final 2011 4 pdf (accessed 25 April 2012).

3. Knowles $\mathrm{S}(\mathrm{ed})$, Cohen $\mathrm{H}$ on behalf of the Serious Hazards of Transfusion (SHOT) Steering Group, The 2010 Anua SHOT Report, Transfusion (SHOT) Stering Group The 2010 An 1 SHOT Report, SHOT, 2011. Available at: www.shotuk.org/shot-reports/reportand-summary-2010-2/ (accessed 25 April 2012).

4. Chapman CE, Stainsby D, Jones H, et al., Serious Hazards of Transfusion Steering Group, Ten years of hemovigilance reports of transfusion-related acute lung injury in the United Kingdom and the impact of preferential use of male donor plasma, Transfusion, 2009;49(3):440-52.

5. Williamson LM, Stainsby D, Jones $\mathrm{H}$, et al., The impact of universal leukodepletion of the blood supply on hemovigilance reports of posttransfusion purpura and transfusion-associated graft-versus-host disease, Transfusion, 2007;47(8):1455-67.
6. Love E, Lowe S, SHOT Report 1996-1997, 1998;1-126. Available at: wnw.shotuk.org (accessed 25 April 2012).

Williamson LM, Lowe S, Love EM, et al., Serious hazards of transfusion (SHOT) initiative: analysis of the first two annual reports, BMJ, 1999;319(7201):16-9.

8. The administration of blood and blood components and the management of transfused patients. British Committee for Standards in Haematology, Blood Transfusion Task Force. Royal College of Nursing and the Royal College of Surgeons of England, Transfus Med, 1999;9(3):227-38.

9. British Committee for Standards in Haematology, Guideline on the Administration of Blood Components, December 2009. Available at: www.bcshguidelines.com/documents/Admin_blood_compone ts_bcsh_05012010.pdf (accessed 25 April 2012).

10. Department of Health, Health Service Circular 1998/224: Better Blood Transfusion, December 1998. Available at: www.dh.gov.uk/en/Publicationsandstatistics/Lettersandcirculars /Healthservicecirculars/DH_4004262 (accessed 25 April 2012).

11. Department of Health, Health Service Circular 2002/009: Better Blood Transfusion: Appropriate Use of Blood, July 2002. Available at: www.dh.gov.uk/en/Publicationsandstatistics/Lettersandcirculars /Healthservicecirculars/DH 4004264 (accessed 25 April 2012).

12. Department of Health, Health Service Circular 2007/001: Better Blood
Transfusion - Safe and Appropriate Use of Blood, London: DH, November 2007. Available at:

uww.dh.gov.uk/en/Publicationsandstatistics/Lettersandcirculars /Healthservicecirculars/DH_080613 (accessed 25 April 2012).

13. Love EM, Soldan $\mathrm{K}$, Jones $\mathrm{H}$, Serious Hazards of Transfusion Steering Group, SHOT Annual Report 2000-2001, 2002. Available at: unw.shotuk.org/shot-reports/reports-and-summaries20002001/ (accessed 25 April 2012).

14. National Patient Safety Agency, Safer Practice Notice 14 - Right Patient, Right Blood, November 2006. Available at: uww.nrls.npsa.nhs.uk/resources/collections/right-patient-rightblood/ (accessed 25 April 2012).

15. Chaffe B, Jones J, Milkins C, et al., UK Transfusion Laboratory Collaborative: recommended minimum standards for hospital transfusion laboratories, Transfus Med, 2009;19(4):156-8.

16. The Blood Safety and Quality Regulations 2005. Available at: www.opsi.gov.uk/si/si2005/20050050.htm (accessed 25 April 2012).

17. National Patient Safety Agency, Rapid Response Report NPSA/2010/RRR017, The transfusion of blood and blood components in an emergency, October 2010. Available at: www.nrls.npsa.nhs.uk/resources/?entryid45=83659\&p $=4$ (accessed 25 April 2012). 